\title{
Implications of Fasting Plasma Glucose Variability on the Risk of Incident Peripheral Artery Disease in a Population without Diabetes: A Nationwide Population-Based Cohort Study
}

Hye Soo Chung

Hallym University

Soon Young Hwang

Korea University

Jung A Kim

Korea University

Eun Roh

Korea University

Hye Jin Yoo

Korea University

Sei Hyun Baik

Korea University

Nan Hee Kim

Korea University

Ji A Seo

Korea University

Sin Gon Kim

Korea University

Nam Hoon Kim

Korea University

Kyung Mook Choi ( $\square$ medica7@gmail.com )

Korea University https://orcid.org/0000-0001-6175-0225

\section{Research Article}

Keywords: glycemic variability, fasting plasma glucose, peripheral artery disease

Posted Date: November 8th, 2021

DOI: https://doi.org/10.21203/rs.3.rs-1050623/v1 
License: (c) (i) This work is licensed under a Creative Commons Attribution 4.0 International License. Read Full License

Version of Record: A version of this preprint was published at Cardiovascular Diabetology on January 31st, 2022. See the published version at https://doi.org/10.1186/s12933-022-01448-1. 


\section{Abstract \\ Background}

Diabetes have been known as a traditional risk factor of developing peripheral artery disease (PAD). However, the impact of long-term glycemic variability on the risk of developing PAD, especially in a general population without diabetes.

\section{Methods}

We included 152,931 individuals without diabetes from the Korean National Health Insurance ServiceHealth Screening Cohort. Fasting plasma glucose (FPG) variability was measured using coefficient variance (FPG-CV), standard deviation (FPG-SD), and variability independent of the mean (FPG-VIM).

\section{Results}

A total of $16,863(11.0 \%)$ incident cases of PAD were identified during a median follow-up of 8.3 years. Kaplan-Meier curves showed a progressively increasing risk of PAD in the higher quartile group of FPG variability than in the lowest quartile group (log rank $P<0.001)$. Multivariable Cox proportional hazard analysis showed the hazard ratio for PAD prevalence as $1.11(95 \% \mathrm{Cl} 1.07-1.16, P<0.001)$ in the highest FPG-CV quartile than in the lowest FPG-CV quartile after adjusting for confounding variables, including mean FPG. Similar degree of association was shown in the FPG-SD and FPG-VIM. In sensitivity analysis, the association between FPG variability and the risk of developing PAD persisted even after the participants were excluded based on previously diagnosed diseases, including stroke, coronary artery disease, congestive heart failure, chronic kidney disease, or current smokers or drinkers. Subgroup analysis demonstrated that the effects of FPG variability on the risk of PAD were more powerful in subgroups of younger age, regular exercisers, and those with higher income.

\section{Conclusion}

Increased long-term glycemic variability may have a significant prognostic effect for incident PAD in individuals without diabetes.

\section{Background}

Peripheral artery disease (PAD) is a chronic arterial occlusive disease caused by atherosclerosis, especially in the lower extremities [1]. In the United States, among individuals aged $>40$ years, the prevalence of PAD was reported at approximately $10.7 \%$ and severe PAD, such as severe limb ischemia, at 1.3\% [2]. Despite its high prevalence, people are still poorly informed regarding the potential risk, pathology, and clinical expression that lead to PAD. Moreover, patients with PAD have a higher incidence 
of cardiovascular disease (CVD) and CVD-related mortality [1, 3]; because both CVD and PAD are atherosclerosis-related ischemic artery diseases that share similar pathogenetic backgrounds. Given the burden, continuous investigation and efforts to reduce the risk factors are advisable.

Several traditional risk factors for atherosclerosis, such as smoking, diabetes, hypertension, and dyslipidemia, have been linked to an increased risk of developing PAD. In particular, the population with diabetes had a 38-84\% higher risk of PAD than the population without diabetes [4]. Furthermore, preceding observational studies have suggested that well-controlled glucose levels measured with fasting plasma glucose (FPG) or glycated hemoglobin (HbA1c) have a beneficial outcome on limb ischemia among patients with diabetes and PAD $[5,6]$.

Recent evidence have proposed glycemic variability to be a novel target of glycemic control; thus, glycemic variability may be an important predictor of atherosclerosis independent of average glucose levels. It has been reported that long-term glycemic variability is positively associated with macrovascular/microvascular complications and mortality in individuals with diabetes [7-9]. In addition, several studies have suggested that increased glycemic fluctuations cause more atherosclerosis-related reactions by stimulating inflammatory cytokines, oxidative stress, endothelial dysfunction, and insulin resistance than sustained hyperglycemia $[10,11]$. In vivo and in vitro studies have also revealed a relationship between glucose fluctuation and endothelial cell/endothelium damage [12-14]. Furthermore, we reported that visit-to-visit variability of FPG may be a significant predictor of chronic cardiometabolic and neurodegenerative diseases, such as type 2 diabetes [15], cardiovascular disease [16], non-alcoholic fatty liver disease [17], and Parkinson's disease [18] in the Korean general population without diabetes.

In this study, we aimed to investigate the association between long-term glycemic variability and the risk of incident PAD in the general population without diabetes using a database from the longitudinal National Health Insurance Service-National Health Screening Cohort (NHIS-HEALS) of the Korean population.

\section{Methods}

\section{Data source and study population}

The NHIS-HEALS is a randomly selected database that includes about $10 \%$ of the general population between 40 and 79 years old within the Korean NHIS database. The Korean NHIS is a governmentmanaged mandatory public health insurance program that provides biennial national health examinations for the general population (18). The Korean NHIS comprises sociodemographic information (such as sex, age, and income), claim data (such as codes of diagnoses, pharmacy, and death), and a national health examination (such as anthropometric measurements, blood pressure, laboratory tests, and standardized self-reported questionnaires on smoking status, alcohol consumption, and exercise). Height, weight, and laboratory tests were done after an overnight fast, and the quality assurance process was supervised by the Korean Association of Laboratory Quality Control. The samples 
were initially collected from 209,226 participants who underwent a health examination in 2007 (index year). Participants were excluded based on the following criteria: those who underwent one or two health examinations from January 1, 2002, to December 31, $2007(n=31,465)$, those who had missing laboratory data for at least one variable $(n=126)$, and individuals who had previously been diagnosed with diabetes and PAD prior to $2007(n=24,704)$. Finally, a total of 152,931 participants were included in the analysis (Fig. 1).

These protocols were approved by the NHIS review committee. The Hallym University Institutional Review Board (IRB) approved the study protocol in accordance with the Declaration of Helsinki of the World Medical Association. Informed consent was waived because anonymous and unidentified information was used for the analysis.

\section{Definition Of Fpg Variability}

The visit-to-visit variability in FPG was defined using three or more FPG levels measured during serial health examinations conducted from January 1,2002, to December 31, 2007. The number of FPG level measurements per participants were as follows: three ( $n=75,688 ; 49.5 \%)$, four ( $n=16,501 ; 10.8 \%)$, five ( $n$ $=22,521 ; 14.7 \%)$, and six $(n=38,221 ; 25.0 \%)$ measurements. Three methods of measurement were used for the calculation of FPG variability that included the coefficient variance (FPG-CV), standard deviation (FPG-SD), and variability independent of the mean (FPG-VIM). The CV was defined as SD/mean $\times 100 \%$, whereas VIM was defined as $\square \times$ SD/Mean ${ }^{\beta}$, where $\beta$ is the regression coefficient based on the natural logarithm of the SD divided by the natural logarithm of the mean ( $\left(=\right.$ Mean(Mean(FPG) $\left.{ }^{\beta}\right)[19]$.

\section{Measurements And Definitions}

The primary outcomes of this study were newly incident PAD that were identified after health examinations in 2007 (index year) until December 2015 or their date of death. PAD was diagnosed using the International Classification of Diseases, Tenth Revision (ICD-10) codes (170.2, 170.9, 173.9, 174.3, and 174.4) [20] in both inpatient and outpatient settings. Diabetes was defined based on the criteria of fasting glucose level $\geq 7.0 \mathrm{mmol} / \mathrm{L}$ or by having at least one prescription claim per year for medication for diabetes under the ICD-10 codes E10-E14. Impaired fasting glucose (IFG) was defined as FPG levels between $5.6 \mathrm{mmol} / \mathrm{L}$ and $6.9 \mathrm{mmol} / \mathrm{L}$ among participants without diabetes. Hypertension was defined based on the criteria of systolic/diastolic blood pressure $\geq 140 / 90 \mathrm{mmHg}$ or by having at least one prescription claim per year for hypertension medication under ICD-10 codes I10-115. Dyslipidemia was defined based on the criteria of total cholesterol $\geq 6.2 \mathrm{mmol} / \mathrm{L}$ or by having at least one prescription claim per year for a dyslipidemia medication under ICD-10 code E78. Stroke diagnosis was defined as ICD-10 codes 160-164 on the admission record with computerized tomography or magnetic resonance imaging claim data. The diagnosis of coronary artery disease (CAD) was defined as ICD-10 codes I50-I25 with coronary artery angiography (HA670). The diagnosis of chronic kidney disease (CKD) was defined as ICD- 
10 codes N18 or N19. The diagnosis of congestive heart failure (CHF) was defined as ICD-10 code I50 during hospitalization. Body mass index (BMI) was calculated as weight in kilograms divided by the square of height in meters $\left(\mathrm{kg} / \mathrm{m}^{2}\right)$. Smoking status and information concerning alcohol consumption were obtained from a questionnaire administered during the health examination. Regular exercise was defined as strenuous physical activity for at least $\mathbf{2 0 ~ m i n ~ o r ~ m o r e ~ t h a n ~ f i v e ~ t i m e s ~ p e r ~ w e e k . ~ I n c o m e ~ l e v e l s ~}$ were dichotomized to the lower $20 \%$ level.

\section{Statistical Analysis}

All participants were classified into quartile groups according to FPG variability values in the baseline characteristics. The data are expressed as mean \pm standard deviation for continuous variables or number of participants (percentages) for categorical variables. The differences between groups of quartiles were calculated using ANOVA or $\chi^{2}$-test, as appropriate. The probability of PAD by quartiles of FPG variability was analyzed using the Kaplan-Meier method, and the log-rank test was used to determine the differences across the groups. We analyzed hazard ratios (HRs) and 95\% $\mathrm{Cl}$ for the development of PAD using Cox proportional hazards models for quartile groups of FPG variability. It was adjusted for age, sex, $\mathrm{BMI}$, smoking status, alcohol consumption, regular exercise, income, hypertension medication, dyslipidemia medication, systolic blood pressure, total cholesterol, history of stroke, history of CAD, history of CKD, and mean FPG. Data were analyzed by an experienced expert statistician (S.Y. Hwang) using SAS Enterprise Guide 7.1 (SAS Institute Inc., Cary, NC, USA); A P-value $<0.05$ was assumed to indicate statistical significance.

\section{Results}

\section{Baseline Characteristics of the Study Population}

Table 1 shows the baseline characteristics of the study participants according to the CV quartiles for FPG variability. Among the 152,931 individuals with complete follow-up data, 16,863 (11.0\%) had incident PAD during the median follow-up period of 8.3 years. The participants in the higher FPG-CV quartile were older and more likely to be of male sex than those in the lower quartile. Moreover, the groups with higher FPG variability had comorbidities, including an increased prevalence of IFG, dyslipidemia, and hypertension with elevated blood pressure level. According to the higher quartiles of FPG variability, participants had higher risk factors based on their unhealthy lifestyles, including smoking, alcohol consumption, and lack of regular exercise. However, FPG variability was not associated with BMI, total cholesterol level, or a history of stroke, CKD, CAD, or CHF. Similar associations of baseline characteristics among the study participants were described according to FPG variability quartiles as determined by SD (Additional file 1) and VIM (Additional file 2). 
Table 1

Baseline characteristics of the participants according to the fasting plasma glucose variability (coefficient of variation)

\begin{tabular}{|c|c|c|c|c|c|}
\hline & Q1 & Q2 & Q3 & Q4 & $\begin{array}{l}P \\
\text { value }\end{array}$ \\
\hline CV range (\%) & $4.32 \pm 1.47$ & $8.02 \pm 0.93$ & $\begin{array}{l}11.53 \pm \\
1.16\end{array}$ & $\begin{array}{l}19.61 \pm \\
8.74\end{array}$ & $<0.001$ \\
\hline$N$ & 38,246 & 38,219 & 38,231 & 38,235 & \\
\hline Age (years) & $\begin{array}{l}55.83 \pm \\
8.77\end{array}$ & $\begin{array}{l}54.93 \pm \\
8.34\end{array}$ & $\begin{array}{l}55.08 \pm \\
8.46\end{array}$ & $\begin{array}{l}56.13 \pm \\
8.95\end{array}$ & $<0.001$ \\
\hline Sex (male) $(n, \%)$ & $\begin{array}{l}19959 \\
(52.19)\end{array}$ & $\begin{array}{l}22,325 \\
(58.41)\end{array}$ & $\begin{array}{l}23,421 \\
(61.26)\end{array}$ & $\begin{array}{l}24,928 \\
(65.2)\end{array}$ & $<.0001$ \\
\hline Body mass index $\left(\mathrm{kg} / \mathrm{m}^{2}\right)$ & $\begin{array}{l}23.82 \pm \\
2.76\end{array}$ & $\begin{array}{l}23.85 \pm \\
2.81\end{array}$ & $\begin{array}{l}23.85 \pm \\
2.81\end{array}$ & $\begin{array}{l}23.87 \pm \\
2.89\end{array}$ & 0.208 \\
\hline Systolic BP (mmHg) & $\begin{array}{l}124.35 \pm \\
15.48\end{array}$ & $\begin{array}{l}124.55 \pm \\
15.48\end{array}$ & $\begin{array}{l}125.08 \pm \\
15.48\end{array}$ & $\begin{array}{l}126.6 \pm \\
15.84\end{array}$ & $<0.001$ \\
\hline Diastolic BP (mmHg) & $\begin{array}{l}77.44 \pm \\
10.1\end{array}$ & $\begin{array}{l}77.83 \pm \\
10.13\end{array}$ & $\begin{array}{l}78.27 \pm \\
10.2\end{array}$ & $\begin{array}{l}79.04 \pm \\
10.24\end{array}$ & $<0.001$ \\
\hline AST (IU/L) & $\begin{array}{l}25.39 \pm \\
14.34\end{array}$ & $\begin{array}{l}25.67 \pm \\
14.08\end{array}$ & $26 \pm 13.53$ & $\begin{array}{l}26.93 \pm \\
16.7\end{array}$ & $<0.001$ \\
\hline ALT (IU/L) & $\begin{array}{l}24.08 \pm \\
18.59\end{array}$ & $\begin{array}{l}24.58 \pm \\
18.82\end{array}$ & $\begin{array}{l}24.82 \pm \\
18.29\end{array}$ & $\begin{array}{l}25.46 \pm \\
19.47\end{array}$ & $<0.001$ \\
\hline GGT (IU/L) & $\begin{array}{l}33.45 \pm \\
41.02\end{array}$ & $\begin{array}{l}35.88 \pm \\
44.34\end{array}$ & $\begin{array}{l}37.61 \pm \\
46.57\end{array}$ & $\begin{array}{l}41.42 \pm \\
54.19\end{array}$ & $<0.001$ \\
\hline Total cholesterol (mg/dL) & $\begin{array}{l}198.34 \pm \\
35.37\end{array}$ & $\begin{array}{l}198.26 \pm \\
35.74\end{array}$ & $\begin{array}{l}198.5 \pm \\
35.89\end{array}$ & $\begin{array}{l}198.8 \pm \\
36.71\end{array}$ & 0.166 \\
\hline Mean FPG (mmol/L) & $5.11 \pm 0.51$ & $5.08 \pm 0.50$ & $5.08 \pm 0.49$ & $5.31 \pm 0.84$ & $<0.001$ \\
\hline Smoking status (n, \%) & & & & & $<0.001$ \\
\hline Non-smoker & $\begin{array}{l}26,256 \\
(68.65)\end{array}$ & $\begin{array}{l}25,178 \\
(65.88)\end{array}$ & $\begin{array}{l}24,528 \\
(64.16)\end{array}$ & $\begin{array}{l}23,518 \\
(61.51)\end{array}$ & \\
\hline Ex-smoker & $3,497(9.14)$ & 3,525 (9.22) & $3,439(9)$ & $\begin{array}{l}3,209 \\
(8.39)\end{array}$ & \\
\hline
\end{tabular}

P-value using ANOVA and Chi-square tests

Data are expressed as mean $\pm S D$, or $n(\%)$.

$\mathrm{CV}$, coefficient of variation; BP, blood pressure; AST, aspartate aminotransferase; ALT, alanine aminotransferase; GGT, $y$-glutamyl transferase; FPG, fasting plasma glucose; IFG, impaired fasting glucose; CKD, chronic kidney disease 


\begin{tabular}{|c|c|c|c|c|c|}
\hline & Q1 & Q2 & Q3 & Q4 & $\begin{array}{l}P \\
\text { value }\end{array}$ \\
\hline Current smoker & $\begin{array}{l}5,574 \\
(14.57)\end{array}$ & $\begin{array}{l}6,591 \\
(17.25)\end{array}$ & $\begin{array}{l}7,250 \\
(18.96)\end{array}$ & $\begin{array}{l}8,658 \\
(22.64)\end{array}$ & \\
\hline Unknown & $2,919(7.63)$ & $2,925(7.65)$ & $3,014(7.88)$ & $\begin{array}{l}2,850 \\
(7.45)\end{array}$ & \\
\hline Alcohol consumption (n, \%) & & & & & $<0.001$ \\
\hline Non-drinker & $\begin{array}{l}27,831 \\
(72.77)\end{array}$ & $\begin{array}{l}26,956 \\
(70.53)\end{array}$ & $\begin{array}{l}26,367 \\
(68.97)\end{array}$ & $\begin{array}{l}25,799 \\
(67.47)\end{array}$ & \\
\hline Drinker & $9,295(24.3)$ & $\begin{array}{l}10,277 \\
(26.89)\end{array}$ & $\begin{array}{l}10,892 \\
(28.49)\end{array}$ & $\begin{array}{l}11,640 \\
(30.44)\end{array}$ & \\
\hline Unknown & $1,120(2.93)$ & $986(2.58)$ & $972(2.54)$ & $796(2.08)$ & \\
\hline Regular exercise (n, \%) & & & & & $<0.001$ \\
\hline None & $\begin{array}{l}16,582 \\
(43.36)\end{array}$ & $\begin{array}{l}16,787 \\
(43.92)\end{array}$ & $\begin{array}{l}17,246 \\
(45.11)\end{array}$ & $\begin{array}{l}18,412 \\
(48.15)\end{array}$ & \\
\hline Regular exercise & $\begin{array}{l}20,531 \\
(53.68)\end{array}$ & $\begin{array}{l}20,366 \\
(53.29)\end{array}$ & $\begin{array}{l}20,015 \\
(52.35)\end{array}$ & $\begin{array}{l}18,983 \\
(49.65)\end{array}$ & \\
\hline Unknown & $1,133(2.96)$ & $1,066(2.79)$ & $970(2.54)$ & $840(2.2)$ & \\
\hline Income (lower 20\%) & $\begin{array}{l}4,738 \\
(12.39)\end{array}$ & $\begin{array}{l}5,130 \\
(13.42)\end{array}$ & $\begin{array}{l}5,577 \\
(14.59)\end{array}$ & $\begin{array}{l}6,387 \\
(16.7)\end{array}$ & $<0.001$ \\
\hline IFG (\%) & $\begin{array}{l}8,465 \\
(22.13)\end{array}$ & $9,249(24.2)$ & $\begin{array}{l}10,958 \\
(28.66)\end{array}$ & $\begin{array}{l}14,758 \\
(38.6)\end{array}$ & $<0.001$ \\
\hline Hypertension & $\begin{array}{l}13,977 \\
(36.54)\end{array}$ & $\begin{array}{l}13,829 \\
(36.18)\end{array}$ & $\begin{array}{l}14,216 \\
(37.18)\end{array}$ & $\begin{array}{l}15,796 \\
(41.31)\end{array}$ & $<0.001$ \\
\hline Dyslipidemia & $\begin{array}{l}7,707 \\
(20.15)\end{array}$ & $\begin{array}{l}7,551 \\
(19.76)\end{array}$ & $\begin{array}{l}7,643 \\
(19.99)\end{array}$ & $\begin{array}{l}7,933 \\
(20.75)\end{array}$ & 0.005 \\
\hline History of Stroke & $200(0.52)$ & $173(0.45)$ & $187(0.49)$ & $215(0.56)$ & 0.172 \\
\hline History of CKD & $135(0.35)$ & $101(0.26)$ & $121(0.32)$ & $119(0.31)$ & 0.179 \\
\hline $\begin{array}{l}\text { History of coronary artery } \\
\text { disease }\end{array}$ & $396(1.04)$ & $403(1.05)$ & $356(0.93)$ & $433(1.13)$ & 0.053 \\
\hline $\begin{array}{l}\text { History of congestive heart } \\
\text { failure }\end{array}$ & $38(0.1)$ & $37(0.1)$ & $41(0.11)$ & $57(0.15)$ & 0.110 \\
\hline \multicolumn{6}{|c|}{ P-value using ANOVA and Chi-square tests } \\
\hline \multicolumn{6}{|c|}{ Data are expressed as mean $\pm S D$, or $n(\%)$} \\
\hline \multicolumn{6}{|c|}{$\begin{array}{l}\text { CV, coefficient of variation; BP, blood pressure; AST, aspartate aminotransferase; } \mathrm{ALT} \text {, alanine } \\
\text { aminotransferase; GGT, Y-glutamyl transferase; FPG, fasting plasma glucose; IFG, impaired fasting } \\
\text { glucose; CKD, chronic kidney disease }\end{array}$} \\
\hline
\end{tabular}




\begin{tabular}{|c|c|c|c|c|c|}
\hline & Q1 & Q2 & Q3 & Q4 & $\begin{array}{l}P \\
\text { value }\end{array}$ \\
\hline $\begin{array}{l}\text { Use of anti-hypertension } \\
\text { medication }\end{array}$ & $\begin{array}{l}14,441 \\
(37.76)\end{array}$ & $\begin{array}{l}14,002 \\
(36.64)\end{array}$ & $\begin{array}{l}14,023 \\
(36.68)\end{array}$ & $\begin{array}{l}15,298 \\
(40.01)\end{array}$ & $<0.001$ \\
\hline $\begin{array}{l}\text { Use of anti-dyslipidemia } \\
\text { agent }\end{array}$ & $\begin{array}{l}4,968 \\
(12.99)\end{array}$ & $\begin{array}{l}4,774 \\
(12.49)\end{array}$ & $\begin{array}{l}4,688 \\
(12.26)\end{array}$ & $\begin{array}{l}5,053 \\
(13.22)\end{array}$ & $<0.001$ \\
\hline \multicolumn{6}{|c|}{ P-value using ANOVA and Chi-square tests } \\
\hline \multicolumn{6}{|c|}{ Data are expressed as mean $\pm S D$, or $n(\%)$. } \\
\hline \multicolumn{6}{|c|}{$\begin{array}{l}\text { CV, coefficient of variation; BP, blood pressure; AST, aspartate aminotransferase; ALT, alanine } \\
\text { aminotransferase; GGT, } Y \text {-glutamyl transferase; FPG, fasting plasma glucose; IFG, impaired fasting } \\
\text { glucose; CKD, chronic kidney disease }\end{array}$} \\
\hline
\end{tabular}

\section{Effect Of Fpg Variability On Incident Pad}

Figure 2 presents the Kaplan-Meier curves of the probability of newly developing PAD for 8 years according to FPG-CV, FPG-SD, and FPG-VIM values. Higher levels of FPG variability were associated with an increased and progressive risk of incident PAD (all of log rank $P<0.001$ ). Moreover, it was observed that the increased risk of developing PAD in the highest quartile group persisted compared to the lowest quartile group.

Table 2 describes the association between FPG variability, using CV, SD, and VIM values, and the risk of developing PAD. In all models, a higher risk of developing PAD was observed in the higher variability quartile groups than in the lowest quartile group. The results were consistent after stepwise adjustment for various confounding factors, including mean FPG. The adjusted HRs of prevalence of PAD in the highest quartile of the FPG variability group, as measured using CV, SD, and VIM, were $1.11(95 \% \mathrm{Cl}$, 1.07-1.16), 1.11 (95\% Cl, 1.06-1.16), and 1.11 (95\% Cl, 1.07-1.16), respectively, compared to the lowest quartile group (all of $P$ for trend $<0.001$ ). 
Table 2

Hazard ratios (HR) and $95 \%$ confidence intervals (Cls) of PAD by quartiles of FPG variability (CV, SD, and $\mathrm{VIM}$ )

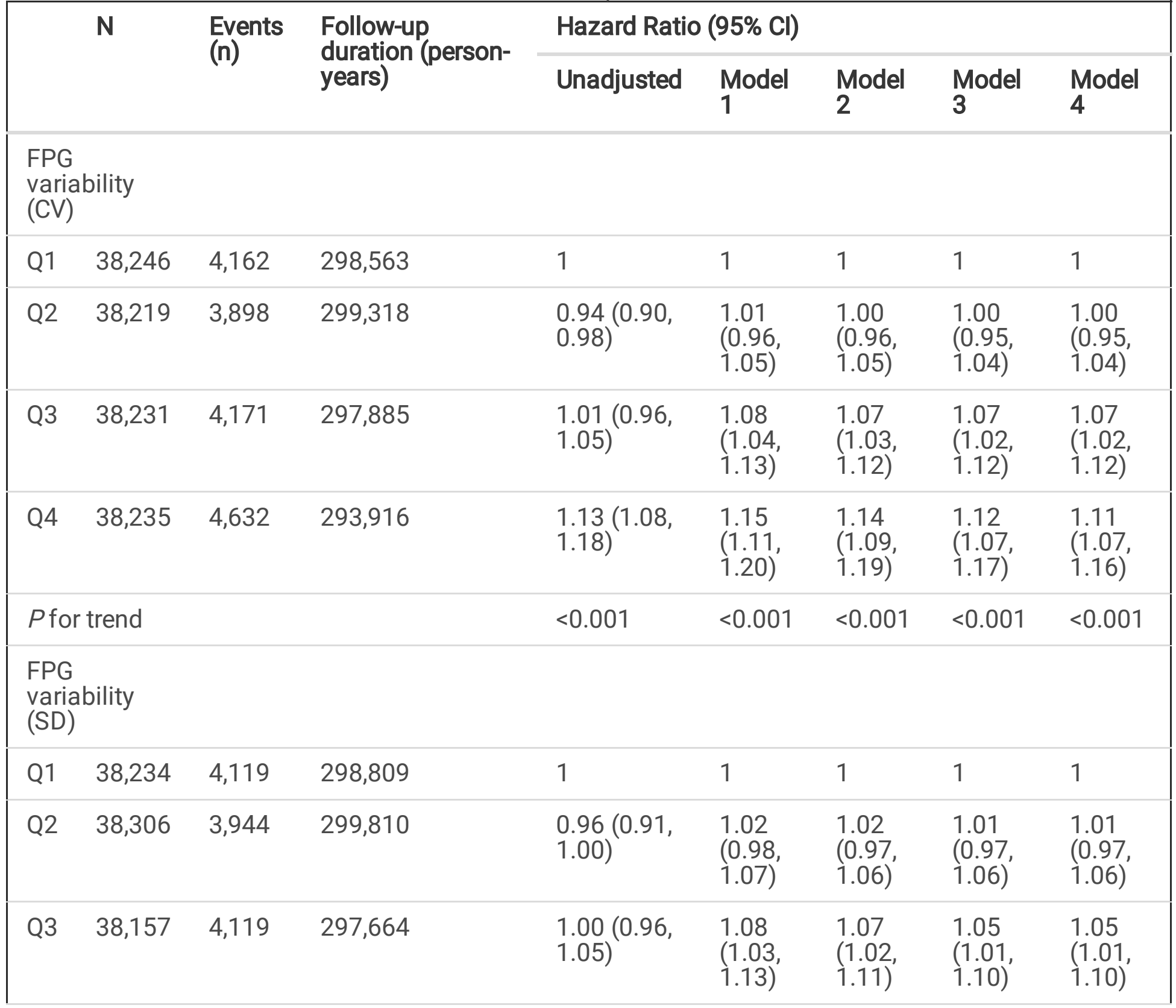

Model 1: Adjusted for age and sex

Model 2: Model 1+ body mass index, smoking status, alcohol consumption, regular exercise, and income.

Model 3: Model 2+ antihypertensive medications, dyslipidemia medications, systolic blood pressure, total cholesterol, history of stroke, history of coronary artery disease, and history of chronic kidney disease

Model 4: Model $3+$ mean FPG

FPG, fasting plasma glucose; CV, coefficient of variation; SD, standard deviation; VIM, variability independent of the mean 


\begin{tabular}{|c|c|c|c|c|c|c|c|c|}
\hline & \multirow[t]{2}{*}{$\mathbf{N}$} & \multirow{2}{*}{$\begin{array}{l}\text { Events } \\
\text { (n) }\end{array}$} & \multirow{2}{*}{$\begin{array}{l}\text { Follow-up } \\
\text { duration (person- } \\
\text { years) }\end{array}$} & \multicolumn{5}{|c|}{ Hazard Ratio (95\% Cl) } \\
\hline & & & & Unadjusted & Model & $\begin{array}{l}\text { Model } \\
2\end{array}$ & $\begin{array}{l}\text { Model } \\
3\end{array}$ & $\begin{array}{l}\text { Model } \\
4\end{array}$ \\
\hline Q4 & 38,234 & 4,681 & 293,400 & $\begin{array}{l}1.16(1.11 \\
1.21)\end{array}$ & $\begin{array}{l}1.18 \\
(1.13 \\
1.23)\end{array}$ & $\begin{array}{l}1.15 \\
(1.11 \\
1.20)\end{array}$ & $\begin{array}{l}1.12 \\
(1.07 \\
1.17)\end{array}$ & $\begin{array}{l}1.11 \\
(1.06 \\
1.16)\end{array}$ \\
\hline \multicolumn{2}{|c|}{$P$ for trend } & & & $<0.001$ & $<0.001$ & $<0.001$ & $<0.001$ & $<0.001$ \\
\hline \multicolumn{9}{|c|}{$\begin{array}{l}\text { FPG } \\
\text { variability } \\
\text { (VIM) }\end{array}$} \\
\hline Q1 & 38,232 & 4,196 & 298,180 & 1 & 1 & 1 & 1 & 1 \\
\hline Q2 & 38,233 & 3,970 & 298,826 & $\begin{array}{l}0.95(0.91 \\
0.99)\end{array}$ & $\begin{array}{l}1.01 \\
(0.97 \\
1.06)\end{array}$ & $\begin{array}{l}1.01 \\
(0.97 \\
1.05)\end{array}$ & $\begin{array}{l}1.00 \\
(0.96 \\
1.05)\end{array}$ & $\begin{array}{l}1.01 \\
(0.96 \\
1.05)\end{array}$ \\
\hline Q3 & 38,233 & 4,132 & 298,022 & $\begin{array}{l}0.99(0.94 \\
1.03)\end{array}$ & $\begin{array}{l}1.07 \\
(1.02 \\
1.12)\end{array}$ & $\begin{array}{l}1.07 \\
(1.02 \\
1.11)\end{array}$ & $\begin{array}{l}1.07 \\
(1.02 \\
1.11)\end{array}$ & $\begin{array}{l}1.07 \\
(1.03 \\
1.12)\end{array}$ \\
\hline Q4 & 38,233 & 4,565 & 294,654 & $\begin{array}{l}1.10(1.06 \\
1.15)\end{array}$ & $\begin{array}{l}1.13 \\
(1.08 \\
1.18)\end{array}$ & $\begin{array}{l}1.13 \\
(1.08 \\
1.17)\end{array}$ & $\begin{array}{l}1.11 \\
(1.07 \\
1.16)\end{array}$ & $\begin{array}{l}1.11 \\
(1.07 \\
1.16)\end{array}$ \\
\hline$P$ fo & trend & & & $<0.001$ & $<0.001$ & $<0.001$ & $<0.001$ & $<0.001$ \\
\hline \multicolumn{9}{|c|}{ Model 1: Adjusted for age and sex } \\
\hline \multicolumn{9}{|c|}{$\begin{array}{l}\text { Model 2: Model } 1+\text { body mass index, smoking status, alcohol consumption, regular exercise, and } \\
\text { income. }\end{array}$} \\
\hline \multicolumn{9}{|c|}{$\begin{array}{l}\text { Model 3: Model } 2+\text { antihypertensive medications, dyslipidemia medications, systolic blood pressure, } \\
\text { total cholesterol, history of stroke, history of coronary artery disease, and history of chronic kidney } \\
\text { disease }\end{array}$} \\
\hline \multicolumn{9}{|c|}{ Model 4: Model 3 + mean FPG } \\
\hline \multicolumn{9}{|c|}{$\begin{array}{l}\text { FPG, fasting plasma glucose; CV, coefficient of variation; SD, standard deviation; VIM, variability } \\
\text { independent of the mean }\end{array}$} \\
\hline
\end{tabular}

In the sensitivity analysis, the association between FPG variability and incident PAD persisted even after the participants were excluded based on previously diagnosed diseases, including stroke (Additional file 3), CAD (Additional file 4), CHF (Additional file 5), CKD (Additional file 6), and current smokers (Additional file 7), or drinkers (Additional file 8), before and after adjusting for multi-variables and mean FPG.

In the stratification of subgroups by age, sex, BMI, IFG, hypertension, dyslipidemia, regular exercise, and income, $p$-values for interaction were significant in the subgroups of age ( $<60 \mathrm{vs.} \geq 60$ years), regular exercise (no vs. yes), and income (lower vs. higher) (Figure 3). In the subgroups of $<60$ years of age, regular exercisers, and those with higher income, the HRs of incident PAD were greater than for those $>60$ 
years of age, non-exercisers, and those with lower incomes in the highest quartile of the FPG variability than in the lowest quartile group. The association between FPG variability and PAD was significant in most subgroups. However, in the no regular exercise subgroup and lower income subgroup, the risks of development PAD according to glycemic fluctuation were attenuated.

\section{Discussion}

In this nationwide population-based study, visit-to-visit variability of FPG was a remarkable predictor of PAD development in individuals without diabetes. These findings may be robust considering an independent association between greater glycemic variability and a higher risk of PAD incidence even after extensive adjustment for atherosclerotic risk parameters, including mean FPG levels. In addition, these results were consistently preserved in the sensitivity analysis by excluding crucial risk factors.

As proven in previous studies, glucose levels play an important role in developing arteriosclerosis in population without diabetes. In the Atherosclerosis Risk in Communities (ARIC) study, HbA1c was significantly associated with the risk of CVD and all-cause mortality in adults without diabetes [21]. Using a meta-analysis of 102 prospective studies, Sarwar et al. showed that the FPG levels were associated with atherosclerosis-related vascular disease in participants without diabetes [22]. A meta-analysis of 17 prospective cohort studies in the Asia Pacific region indicated that the FPG levels was a critical risk factor for cardiovascular disease, and that there were significant potential benefits to reducing fasting glucose levels to at least $4.9 \mathrm{mmol} / \mathrm{l}$ in participants with/without diabetes [23]

Additionally, reducing glycemic variability is an emerging glycemic target, and has been suggested as a critical predictor of cardiovascular complications. Several observational studies [7] and post-hoc analysis of trials, including the Action in Diabetes and Vascular Disease: Preterax and Diamicron MR Controlled Evaluation (ADVANCE) trial [9], the Veterans Affairs Diabetes Trial (VADT) [24], the Trial Comparing Cardiovascular Safety of Insulin Degludec vs. Insulin Glargine in Patients with Type 2 Diabetes at High Risk of Cardiovascular Events (DEVOTE) [25], the Action to Control Cardiovascular Risk in Diabetes (ACCORD) trial [26], and the Empagliflozin Cardiovascular Outcome Event (EMPA-REG OUTCOME) trial [27] demonstrated a positive association between visit-to-visit glycemic variability and the risk of micro/macrovascular disease in participants with type 2 diabetes. Furthermore, long-term glycemic variability has also been suggested to affect cardiovascular disease and mortality even in individuals without diabetes. [16, 28].

Recently, several studies have investigated the effect of glycemic variability on PAD development in patients with diabetes. In an Italian multicenter study, Penno et al. showed that HbA1c-SD correlated with lower extremity PAD and severe PAD, such as ulceration/gangrene in patients with type 2 diabetes. [29]. A meta-analysis showed that increased $\mathrm{HbA} 1 \mathrm{c}$ variability was associated with a higher risk of severe PAD in patients with type 2 diabetes [7]. In a population-based cohort in Taiwan Yang et al. demonstrated a significant association between FPG-CV and development of PAD, independent of HbA1c levels, in participants with type 2 diabetes [30]. However, various confounding factors, such as medications for 
diabetes and compliance by patients in their use as well as other diabetes-related complications, might affect their relationship in patients with diabetes. Sun et al. showed a positive relationship between FPG variability and the risk of PAD even in individuals without diabetes, using the ARIC study cohort from US database [31]. However, Sun et al.'s study was performed based on only three measurements of FPG levels. Furthermore, they simply adjusted for baseline FPG as a confounding factor along with other cardiovascular risk factors, and did not use the mean FPG levels. Because FPG is known as a critical risk factor for atherosclerotic cardiovascular disease, in addition to glycemic variability, the mean FPG levels during study period might also affect the final result.

In this study, the participants in the highest quartile of FPG variability presented a similar increased risk of PAD incidence as those in the lowest quartile, as observed using three different methods: FPG-CV, FPGSD, and FPG-VIM. Moreover, the main findings were consistent in diverse sensitivity analysis, excluding populations with a history of stroke, CAD, CHF, CKD, smoking, or drinking, which may support the robustness of the findings in this study. In addition, the present study, that included an Asian population with a relatively lower risk of PAD than the Caucasian population, may broaden the insights into the relationship between glycemic variability and atherosclerosis.

The pathophysiological mechanisms that link the association between long-term FPG variability and PAD are still unknown; thus, further research is required. There are some possible explanations for why high glycemic variability could be a risk factor for PAD incidence. First, glycemic variability, regardless of persistent hyperglycemia, could play a crucial role in atherosclerosis by increasing chronic inflammation, oxidative stress, endothelial dysfunction, and insulin resistance [10-13]. Second, glycemic variation may lead to pancreatic beta cell dysfunction and apoptosis [32]. Furthermore, metabolic memory, and chromatin remodeling caused by repeated glycemic fluctuations, could induce atherosclerosis [33]. Third, glycemic variability may induce cardiovascular autonomic dysfunction with sympathetic activation that may contribute to atherosclerosis [34-36]. It has been reported that patients with PAD have decreased heart rate variability than those without PAD in type 2 diabetes, which implies cardiovascular autonomic dysfunction [34]. Lastly, individuals with high glycemic variability tended to have more traditional risk factors, such as advanced age, high BMI, smoking history, high blood pressure, and dyslipidemia. The present study attempted to alleviate their influence using various sensitivity analyses and extensive adjustment for diverse confounding factors.

Different effects of FPG variability on the risk of PAD were observed across subgroups of age, exercise, and income. In younger individuals ( $<60$ years), regular exercisers, and those with higher income, FPG variability was associated with a higher risk of PAD than in those of older age ( $\geq 60$ years), non-regular exercisers, and those with lower income. Although statistically insignificant, Sun et al. also showed that individuals aged $<60$ years had a higher risk of PAD using FPG-CV and FPG-SD than individuals aged $\geq 60$ years among those without diabetes [31]. In epidemiologic studies, PAD is more common in older age [37], sedentary lifestyle [38], and low socioeconomic status [39, 40]. This study showed that increased FPG variability had a greater impact on the risk of PAD in relatively favorable conditions for cardiovascular risk. 
This study has several limitations. Other assessments of glycemic levels, including $\mathrm{HbA} 1 \mathrm{c}$ or oral glucose tolerance tests, were not used in the health checkup data by the NHIS. In addition, PAD was defined by physicians' diagnostic codes of the ICD-10; thus, under- or over-diagnosis of PAD could be possible. In this study, the prevalence of PAD was $11 \%$, similar to that $(10.7 \%)$ of a large cohort study of individuals aged 40 or older in the United States [2]. Previous studies also defined PAD based on medical claim codes $[2,30]$. We used the ICD-10 code number according to the American Heart Association [20]. Lastly, although we tried to adjust for diverse confounding variables that likely influenced the incidence of PAD, the probability of residual confounding variables cannot be excluded. However, this study has several noteworthy strengths. This study had a large sample size, extensive information about potential confounding variables, and sufficient duration of observation, using a standardized database validated by the Korean government. In particular, we showed coincident and consistent implications for PAD incidence according to long-term glycemic variability determined by three different indices, FPG-CV, FPGSD, and FPG-VIM, even after adjusting for multiple confounding variables including average FPG. Additionally, we used samples taken from the participants representing the entire Korean population; thus, these findings may reflect the real-world situation.

\section{Conclusion}

In conclusion, regardless of average FPG levels and other risk factors, visit-to-visit FPG variability was positively associated with long-term risk of PAD in a general population without diabetes. These findings revealed that reducing glycemic variability may be a potential target for the prevention of PAD. Further investigation is needed to generalize these findings and to better understand the development of PAD, especially in the population without diabetes.

\section{Abbreviations}

AHA, American Heart Association; BMI, body mass index; CAD, coronary artery disease; $\mathrm{Cl}$, confidence interval; $\mathrm{CHF}$, congestive heart failure; CKD, chronic kidney disease; CV, coefficient of variation; CVD, cardiovascular disease; FPG, fasting plasma glucose; HbA1c, Hemoglobin A1C; HRs, hazard ratios; ICD10, International Classification of Diseases Tenth Revision; IFG, impaired fasting glucose; NHIS-HEALS, National Health Insurance Service-National Health Screening Cohort; PAD, peripheral artery disease; SD, standard deviation; VIM, variability independent of the mean

\section{Declarations}

\section{Ethics approval and consent to participate}

The Hallym University Institutional Review Board (IRB) approved the study protocol in accordance with the Declaration of Helsinki of the World Medical Association (IRB approval number: HKS 2021-01-017).

\section{Consent for publication}


Not applicable.

\section{Availability of data and materials}

The datasets generated and/or analyzed during the current study are not publicly available but are available from the corresponding author on reasonable request.

\section{Competing interests}

The authors declare that they have no competing interests

\section{Funding}

This study was supported in part by Korea University Guro Hospital (Korea Research-Driven Hospital), and a grant funded by Korea University Medicine (K2115701, K.M.C.) and by the National Research Foundation of Korea (NRF- 2018R1D1A1B07049605, H.S.C.).

\section{Authors' contributions:}

Conceptualization: HSC, SYH, KMC

Data curation: HSC, SYH, KMC

Formal Analysis: HSC, SYH, KMC

Investigation: HSC, SYH, JAK, ER, HJY, KMC

Methodology: HSC, KMC

Project administration: HSC, KMC

Resources: HSC, SYH, JAK, ER, HJY, SHB, NHK1, JAS, SGK, NHK2, KMC

Supervision: NHK1, JAS, SGK, NHK2, and SHB.

Visualization: HSC, SYH, KMC

Writing - original draft: HSC, KMC

Writing - review \& editing: HSC, SYH, JAK, ER, HJY, SHB, NHK1, JAS, SGK, NHK2, KMC

\section{Acknowledgements.}

This study used data from the National Health Insurance Service-National Health Screening Cohort (NHIS2021-2-146). The authors thank the staff of the National Health Insurance Sharing Service. 


\section{References}

1. Ankle Brachial Index C, Fowkes FG, Murray GD, Butcher I, Heald CL, Lee RJ, Chambless LE, Folsom AR, Hirsch AT, Dramaix M et al: Ankle brachial index combined with Framingham Risk Score to predict cardiovascular events and mortality: a meta-analysis. JAMA 2008, 300(2):197-208.

2. Nehler MR, Duval S, Diao L, Annex BH, Hiatt WR, Rogers K, Zakharyan A, Hirsch AT: Epidemiology of peripheral arterial disease and critical limb ischemia in an insured national population. $J$ Vasc Surg 2014, 60(3):686-695 e682.

3. Unkart JT, Allison MA, Araneta MRG, Ix JH, Matsushita K, Criqui MH: Burden of Peripheral Artery Disease on Mortality and Incident Cardiovascular Events. Am J Epidemio/ 2020, 189(9):951-962.

4. Fowkes FG, Rudan D, Rudan I, Aboyans V, Denenberg JO, McDermott MM, Norman PE, Sampson UK, Williams LJ, Mensah GA et al: Comparison of global estimates of prevalence and risk factors for peripheral artery disease in 2000 and 2010: a systematic review and analysis. Lancet 2013, 382(9901):1329-1340.

5. Singh S, Armstrong EJ, Sherif W, Alvandi B, Westin GG, Singh GD, Amsterdam EA, Laird JR: Association of elevated fasting glucose with lower patency and increased major adverse limb events among patients with diabetes undergoing infrapopliteal balloon angioplasty. Vasc Med 2014, 19(4):307-314.

6. Takahara M, Kaneto H, lida O, Gorogawa S, Katakami N, Matsuoka TA, Ikeda M, Shimomura I: The influence of glycemic control on the prognosis of Japanese patients undergoing percutaneous transluminal angioplasty for critical limb ischemia. Diabetes Care 2010, 33(12):2538-2542.

7. Gorst C, Kwok CS, Aslam S, Buchan I, Kontopantelis E, Myint PK, Heatlie G, Loke Y, Rutter MK, Mamas MA: Long-term Glycemic Variability and Risk of Adverse Outcomes: A Systematic Review and Metaanalysis. Diabetes Care 2015, 38(12):2354-2369.

8. Yang YF, Li TC, Li Cl, Liu CS, Lin WY, Yang SY, Chiang JH, Huang CC, Sung FC, Lin CC: Visit-to-Visit Glucose Variability Predicts the Development of End-Stage Renal Disease in Type 2 Diabetes: 10-Year Follow-Up of Taiwan Diabetes Study. Medicine (Baltimore) 2015, 94(44):e1804.

9. Hirakawa Y, Arima H, Zoungas S, Ninomiya T, Cooper M, Hamet P, Mancia G, Poulter N, Harrap S, Woodward $\mathrm{M}$ et al: Impact of visit-to-visit glycemic variability on the risks of macrovascular and microvascular events and all-cause mortality in type 2 diabetes: the ADVANCE trial. Diabetes Care 2014, 37(8):2359-2365.

10. Ceriello A, Esposito K, Piconi L, Ihnat MA, Thorpe JE, Testa R, Boemi M, Giugliano D: Oscillating glucose is more deleterious to endothelial function and oxidative stress than mean glucose in normal and type 2 diabetic patients. Diabetes 2008, 57(5):1349-1354.

11. Monnier L, Mas E, Ginet C, Michel F, Villon L, Cristol JP, Colette C: Activation of oxidative stress by acute glucose fluctuations compared with sustained chronic hyperglycemia in patients with type 2 diabetes. JAMA 2006, 295(14):1681-1687. 
12. Quagliaro L, Piconi L, Assaloni R, Martinelli L, Motz E, Ceriello A: Intermittent high glucose enhances apoptosis related to oxidative stress in human umbilical vein endothelial cells: the role of protein kinase $C$ and NAD(P)H-oxidase activation. Diabetes 2003, 52(11):2795-2804.

13. Azuma K, Kawamori R, Toyofuku Y, Kitahara Y, Sato F, Shimizu T, Miura K, Mine T, Tanaka Y, Mitsumata $\mathrm{M}$ et al: Repetitive fluctuations in blood glucose enhance monocyte adhesion to the endothelium of rat thoracic aorta. Arterioscler Thromb Vasc Biol 2006, 26(10):2275-2280.

14. Piconi L, Quagliaro L, Assaloni R, Da Ros R, Maier A, Zuodar G, Ceriello A: Constant and intermittent high glucose enhances endothelial cell apoptosis through mitochondrial superoxide overproduction. Diabetes Metab Res Rev 2006, 22(3):198-203.

15. Kim JA, Lee JS, Chung HS, Roh E, Lee YB, Hong SH, Kim NH, Yoo HJ, Seo JA, Kim SG et al: Impact of Visit-to-Visit Fasting Plasma Glucose Variability on the Development of Type 2 Diabetes: A Nationwide Population-Based Cohort Study. Diabetes Care 2018, 41(12):2610-2616.

16. Yu JH, Han K, Park S, Lee DY, Nam GE, Seo JA, Kim SG, Baik SH, Park YG, Kim SM et al: Effects of long-term glycemic variability on incident cardiovascular disease and mortality in subjects without diabetes: A nationwide population-based study. Medicine (Baltimore) 2019, 98(29):e16317.

17. Hong SH, Lee JS, Kim JA, Lee YB, Roh E, Hee Yu J, Kim NH, Yoo HJ, Seo JA, Kim SG et al: Glycemic variability and the risk of nonalcoholic fatty liver disease: A nationwide population-based cohort study. Diabetes Res Clin Pract 2021, 177:108922.

18. Chung HS, Lee JS, Kim JA, Roh E, Lee YB, Hong SH, Yu JH, Kim NH, Yoo HJ, Seo JA et al: Fasting plasma glucose variability in midlife and risk of Parkinson's disease: A nationwide population-based study. Diabetes Metab 2021, 47(3):101195.

19. Rothwell PM, Howard SC, Dolan E, O'Brien E, Dobson JE, Dahlof B, Sever PS, Poulter NR: Prognostic significance of visit-to-visit variability, maximum systolic blood pressure, and episodic hypertension. Lancet 2010, 375(9718):895-905.

20. Virani SS, Alonso A, Aparicio HJ, Benjamin EJ, Bittencourt MS, Callaway CW, Carson AP, Chamberlain AM, Cheng S, Delling FN et al: Heart Disease and Stroke Statistics-2021 Update: A Report From the American Heart Association. Circulation 2021, 143(8):e254-e743.

21. Selvin E, Steffes MW, Zhu H, Matsushita K, Wagenknecht L, Pankow J, Coresh J, Brancati FL: Glycated hemoglobin, diabetes, and cardiovascular risk in nondiabetic adults. N Engl J Med 2010, 362(9):800-811.

22. Emerging Risk Factors C, Sarwar N, Gao P, Seshasai SR, Gobin R, Kaptoge S, Di Angelantonio E, Ingelsson E, Lawlor DA, Selvin E et al: Diabetes mellitus, fasting blood glucose concentration, and risk of vascular disease: a collaborative meta-analysis of 102 prospective studies. Lancet 2010, 375(9733):2215-2222.

23. Lawes CM, Parag V, Bennett DA, Suh I, Lam TH, Whitlock G, Barzi F, Woodward M, Asia Pacific Cohort Studies C: Blood glucose and risk of cardiovascular disease in the Asia Pacific region. Diabetes Care 2004, 27(12):2836-2842. 
24. Zhou JJ, Schwenke DC, Bahn G, Reaven P, Investigators V: Glycemic Variation and Cardiovascular Risk in the Veterans Affairs Diabetes Trial. Diabetes Care 2018, 41(10):2187-2194.

25. Zinman B, Marso SP, Poulter NR, Emerson SS, Pieber TR, Pratley RE, Lange M, Brown-Frandsen K, Moses A, Ocampo Francisco AM et al: Day-to-day fasting glycaemic variability in DEVOTE: associations with severe hypoglycaemia and cardiovascular outcomes (DEVOTE 2). Diabetologia 2018, 61(1):48-57.

26. Sheng CS, Tian J, Miao Y, Cheng Y, Yang Y, Reaven PD, Bloomgarden ZT, Ning G: Prognostic Significance of Long-term HbA1c Variability for All-Cause Mortality in the ACCORD Trial. Diabetes Care 2020, 43(6):1185-1190.

27. Ceriello A, Ofstad AP, Zwiener I, Kaspers S, George J, Nicolucci A: Empagliflozin reduced long-term $\mathrm{HbA} 1 \mathrm{c}$ variability and cardiovascular death: insights from the EMPA-REG OUTCOME trial. Cardiovasc Diabetol 2020, 19(1):176.

28. Wang A, Liu X, Xu J, Han X, Su Z, Chen S, Zhang N, Wu S, Wang Y, Wang Y: Visit-to-Visit Variability of Fasting Plasma Glucose and the Risk of Cardiovascular Disease and All-Cause Mortality in the General Population. J Am Heart Assoc 2017, 6(12).

29. Penno G, Solini A, Zoppini G, Orsi E, Fondelli C, Zerbini G, Morano S, Cavalot F, Lamacchia O, Trevisan $\mathrm{R}$ et al: Hemoglobin A1c variability as an independent correlate of cardiovascular disease in patients with type 2 diabetes: a cross-sectional analysis of the renal insufficiency and cardiovascular events (RIACE) Italian multicenter study. Cardiovasc Diabetol 2013, 12:98.

30. Yang CP, Lin CC, Li Cl, Liu CS, Lin CH, Hwang KL, Yang SY, Li TC: Fasting plasma glucose variability and $\mathrm{HbA} 1 \mathrm{c}$ are associated with peripheral artery disease risk in type 2 diabetes. Cardiovasc Diabetol 2020, 19(1):4.

31. Sun XT, Zeng C, Zhang SZ, Zhou HM, Zhong XB, Xiong ZY, Yang DY, Guo Y, Zhuang XD, Liao XX: Long-term tracking of fasting blood glucose variability and peripheral artery disease in people without diabetes. BMJ Open Diabetes Res Care 2020, 8(1).

32. Del Guerra S, Grupillo M, Masini M, Lupi R, Bugliani M, Torri S, Boggi U, Del Chiaro M, Vistoli F, Mosca $\mathrm{F}$ et al: Gliclazide protects human islet beta-cells from apoptosis induced by intermittent high glucose. Diabetes Metab Res Rev 2007, 23(3):234-238.

33. Keating ST, El-Osta A: Glycemic memories and the epigenetic component of diabetic nephropathy. Curr Diab Rep 2013, 13(4):574-581.

34. Canani LH, Copstein E, Pecis M, Friedman R, Leitao CB, Azevedo MJ, Triches C, Rados DR, Moreas RS, Gross JL: Cardiovascular autonomic neuropathy in type 2 diabetes mellitus patients with peripheral artery disease. Diabetol Metab Syndr 2013, 5(1):54.

35. Matsutani D, Sakamoto M, Minato S, Kayama Y, Takeda N, Horiuchi R, Utsunomiya K: Visit-to-visit $\mathrm{HbA} 1 \mathrm{c}$ variability is inversely related to baroreflex sensitivity independently of $\mathrm{HbA} 1 \mathrm{c}$ value in type 2 diabetes. Cardiovasc Diabetol 2018, 17(1):100.

36. Takei $\mathrm{Y}$, Tomiyama $\mathrm{H}$, Tanaka $\mathrm{N}$, Yamashina A: Close relationship between sympathetic activation and coronary microvascular dysfunction during acute hyperglycemia in subjects with atherosclerotic 
risk factors. Circ J 2007, 71(2):202-206.

37. Allison MA, Ho E, Denenberg JO, Langer RD, Newman AB, Fabsitz RR, Criqui MH: Ethnic-specific prevalence of peripheral arterial disease in the United States. Am J Prev Med 2007, 32(4):328-333.

38. Berger JS, Hochman J, Lobach I, Adelman MA, Riles TS, Rockman CB: Modifiable risk factor burden and the prevalence of peripheral artery disease in different vascular territories. J Vasc Surg 2013, 58(3):673-681 e671.

39. Pande RL, Creager MA: Socioeconomic inequality and peripheral artery disease prevalence in US adults. Circ Cardiovasc Qual Outcomes 2014, 7(4):532-539.

40. Vart P, Coresh J, Kwak L, Ballew SH, Heiss G, Matsushita K: Socioeconomic Status and Incidence of Hospitalization With Lower-Extremity Peripheral Artery Disease: Atherosclerosis Risk in Communities Study. J Am Heart Assoc 2017, 6(8).

\section{Figures}

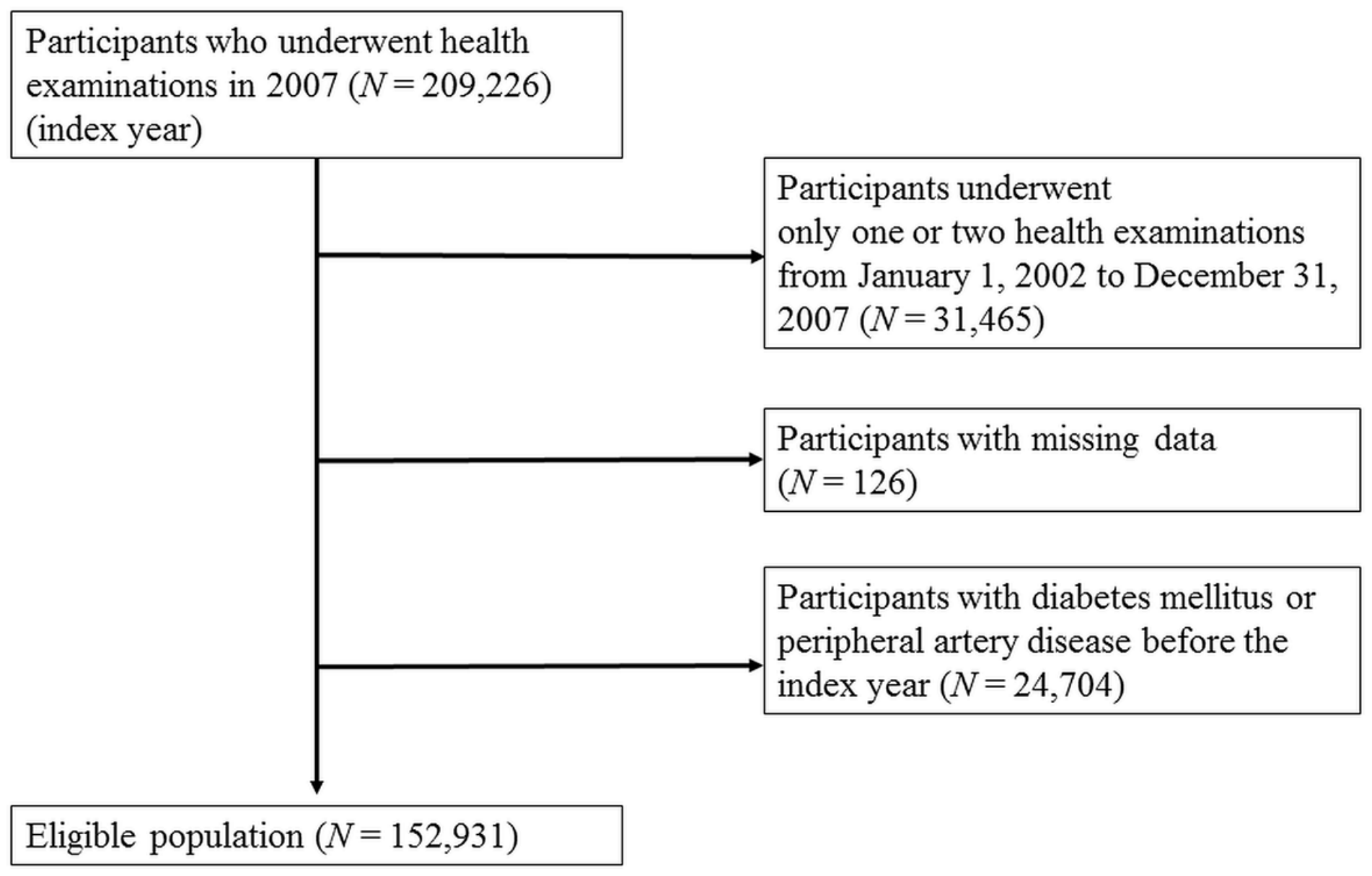

\section{Figure 1}

Flowchart for inclusion of the study population 
(A)

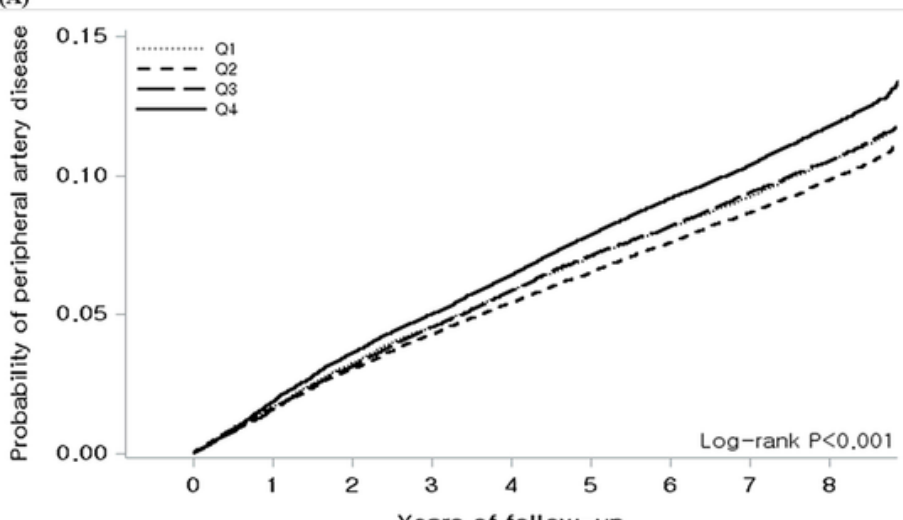

Q1 $38246 \quad 37550 \quad 36817 \quad 36181 \quad 35535 \quad 34910 \quad 34334 \quad 33715 \quad 33060$

Q2 $3821937526 \quad 3688436274 \quad 3568435127345473395533336$ $\begin{array}{lllllllll}38231 & 37536 & 36820 & 36161 & 35514 & 34875 & 34312 & 33661 & 33055\end{array}$

Q4 $38235373753653835803 \quad 3505634270334913282032075$

(B)

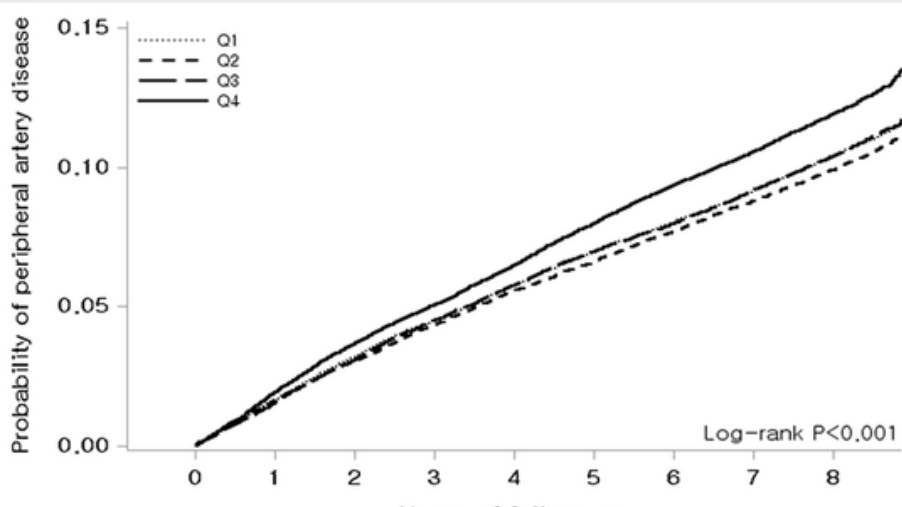

Years of follow-up

Q1 $38234 \quad 37548 \quad 36827 \quad 36205 \quad 35574 \quad 34951 \quad 34370 \quad 33767 \quad 33110$

Q2 $\quad 38306 \quad 37607 \quad 36953 \quad 36332 \quad 35713 \quad 35170 \quad 34587 \quad 3398033391$

Q3 381573748536778361103547634852343053366733029

Q4 $382343734736501 \quad 35772 \quad 35026 \quad 3420933422 \quad 3273731996$

(C)

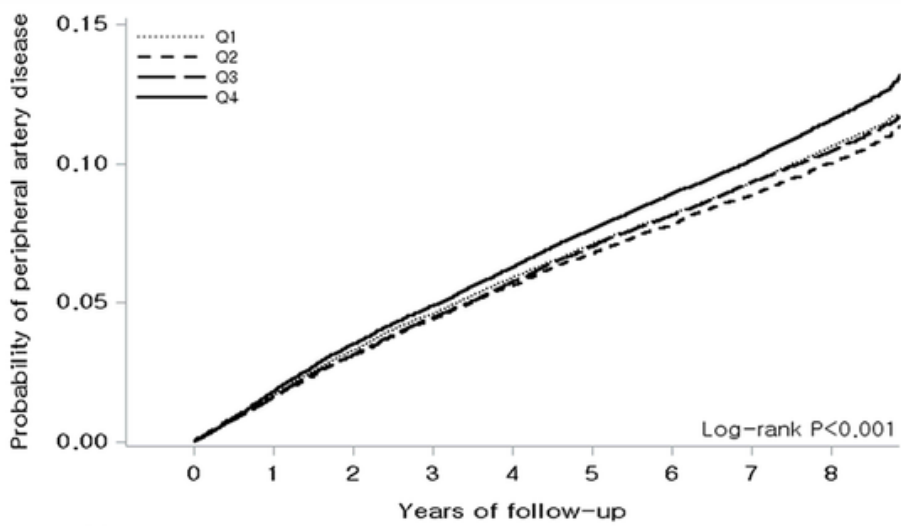

Q1 $3823237523 \quad 36783 \quad 36140 \quad 3549034873 \quad 342943364532985$

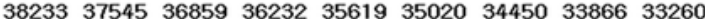
$\begin{array}{llllllllll}38233 & 37520 & 36830 & 36191 & 35549 & 34905 & 34301 & 33681 & 33090\end{array}$

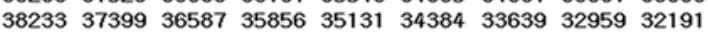

\section{Figure 2}

Kaplan-Meier estimates of the probability of peripheral artery disease (PAD) expressed as quartiles of fasting plasma glucose (FPG) variability (A) FPG variability (FPG - CV: coefficient of variance) (B) FPG variability (FPG - SD: standard deviation) (C) FPG variability (FPG - VIM: variability independent of the mean) 
Subgroup analysis

\begin{tabular}{|c|c|c|c|c|}
\hline Age (years) & & & & 0.039 \\
\hline$<60$ & $\longmapsto$ & $1.17(1.10 .1 .24)$ & $<0.001$ & \\
\hline$\geq 60$ & $\mapsto$ & $1.07(1.01 .1 .13)$ & 0.026 & \\
\hline Gender & & & & 0.545 \\
\hline Male & $\longmapsto$ & $1.12(1.06 .1 .19)$ & $<0.001$ & \\
\hline Female & $\longmapsto$ & $1.09(1.03 .1 .16)$ & 0.003 & \\
\hline B. VI $(\mathrm{kg} / \mathrm{m} 2)$ & & & & 0.552 \\
\hline$<25$ & $\longmapsto$ & $1.10(1.04,1.16)$ & 0.001 & \\
\hline$\geq 25$ & $\longmapsto$ & $1.12(1.05 .1 .20)$ & 0.001 & \\
\hline IFG & & & & 0.925 \\
\hline No & $\longmapsto$ & $1.11(1.05,1.17)$ & $<0.001$ & \\
\hline Yes & $\longmapsto$ & $1.11(1.03 .1 .20)$ & 0.008 & \\
\hline HTN & & & & 0.832 \\
\hline No & $\longmapsto$ & $1.12(1.05 .1 .20)$ & 0.001 & \\
\hline Yes & $\longmapsto$ & $1.11(1.05 .1 .17)$ & 0.000 & \\
\hline HTN medication & & & & 0.676 \\
\hline No & $\longmapsto$ & $1.12(1.05 .1 .20)$ & 0.001 & \\
\hline Yes & $\longmapsto 1$ & $1.10(1.04 .1 .16)$ & 0.001 & \\
\hline Dyslipidemia & & & & 0.235 \\
\hline No & $\mapsto-1$ & $1.09(1.04 .1 .14)$ & 0.001 & \\
\hline Yes & $\longmapsto$ & $1.15(1.06 .1 .25)$ & 0.001 & \\
\hline Dyslipidemia medication & & & & 0.128 \\
\hline No & $\mapsto \bullet$ & $1.09(1.04,1.14)$ & 0.001 & \\
\hline Yes & $\longmapsto$ & $1.18(1.08 .1 .30)$ & 0.001 & \\
\hline Regular exercise & & & & 0.023 \\
\hline No & $\bullet-1$ & $1.06(1.00 .1 .12)$ & 0.052 & \\
\hline Yes & $\longmapsto$ & $1.17(1.10 .1 .24)$ & $<0.001$ & \\
\hline Income & & & & 0.043 \\
\hline Low & $\longrightarrow$ & $1.01(0.91 .1 .11)$ & 0.914 & \\
\hline High & $\mapsto-1$ & $1.13(1.08 .1 .18)$ & $<0.001$ & \\
\hline
\end{tabular}

Figure 3

Association between fasting plasma glucose (FPG) variability and peripheral artery disease (PAD) in a subgroup analysis. *Hazard ratios for PAD in the highest quartile of FPG variability in reference to the lowest quartile. Abbreviations: BMl; body mass index; IFG; impaired fasting glucose; HTN: hypertension

\section{Supplementary Files}

This is a list of supplementary files associated with this preprint. Click to download.

- SupplementarymaterialvFPGPAD.docx 